\title{
Capacity optimization of concentrated solar power-photovoltaic- wind power combined generation system
}

\author{
Huanjin Pei ${ }^{1}$, Su Guo ${ }^{1, *}, Y i \mathrm{He}^{1}$ and Jiale Wang ${ }^{1}$ \\ ${ }^{1}$ College of Energy and Electrical Engineering, Hohai University, Nanjing, China
}

\begin{abstract}
Due to the fluctuation and randomness of renewable resources, such as solar irradiation resource and wind resource, independent renewable power plants are not easy to generate stable and reliable power. However, multi-energy complementary power generation with energy storage can improve the power quality of renewable energy generation and meet the requirements of grid-connected, so it will be the mainstream of renewable energy generation in the future. Capacity optimization of multi-energy complementary system is the basis and key to improve the power quality and reduce cost of renewable power generation. This paper describes the capacity optimization model of concentrated solar powerphotovoltaic-wind (CSP-PV-Wind) combined power generation system. The optimization objectives are as follows: (1) the power is as close to the load as possible; (2) the low overall investment of the combined power supply; (3) the high annual total power generation revenue. The improved particle swarm optimization algorithm is used to optimize the capacity configuration of CSP-PV-Wind combined power generation system, and obtain the optimal dispatch strategy. The results show that, power quality of CSPPV-Wind combined power generation system is obviously better than that of PV-wind combined power generation system, while Surplus of Power Supply Probability (SPSP) and Loss of Power Supply Probability (LPSP) are all below 15\%. However the power generation cost is still a little higher. Therefore, the strategy of reducing the area of collector and increasing the storage tank capacity will be used to decrease the generation cost in the future.
\end{abstract}

\section{Introduction}

With the redundant solar and wind energy resources in China, solar and wind energy are utilized efficiently to solve a series of problems such as energy shortage and environmental pollution caused by the increasing shortage of conventional energy. Solar energy and wind energy are the most widely used, fastest developing and most mature new energy sources, with the advantages such as inexhaustible, widely distributed, pollution-free, non-destructive, cycle-by-cycle, renewable and so on. However, due to the characteristics of randomness, fluctuation and intermittence, the power only provided by photovoltaic (PV) or wind energy are not easy to be stable and reliable. Multi-energy complementary power generation system is proposed to solve this problems, while capacity optimization is the basis and the key of improving the quality of multi-energy complementary power generation and reduce the cost of power generation.

The researches on the multi-energy complementary operation in the world mainly focus on the combined operation of wind farm and PV plant with battery storage or pumped storage. Such as $\mathrm{Xu}$ et al. [1] proposed a capacity optimization system of wind/solar complementary without storage, which improves the reliability of power supply and reduces the investment cost of the system. In the traditional optimization decision variables, factors such as type and capacity of wind turbines and inclination of photovoltaic modules are added. Loss of Power Supply Probability (LPSP) is taken as the reliability index of power supply. The genetic algorithm with elite strategy and adaptive penalty function method is used to solve the mathematical model. Li et al. [2] proposed a calculation model of off-grid wind/solar/storage complementary power generation system based on National Aeronautics and Space Administration (NASA) meteorological database. A program for calculating and optimizing the configuration of this system was developed, while the rationality of the model is verified. Yang et al. [3] proposed an improved differential evolution algorithm to optimize the design of wind/solar complementary power supply system. This method takes into account the local geographical location, wind speed, sunshine, load changes, wind speed model and the inclination of photovoltaic panels and so on, and adopts a mathematical model considering the characteristics of components. Wu et al. [4-6] proposed a multi-objective optimization function for wind power/PV/hybrid-energystorage system. The capacity of storage battery and supercapacitor was optimized by genetic algorithm, which reduced the construction cost of energy storage unit and improved the utilization of renewable energy. 
Yang et al. [7-9] studied the capacity optimization of wind power and solar thermal power complementary system with heat storage. A mixed integer programming dispatching model that take the minimum deviation of output power and load and the maximization of energy utilization as objective functions was established to reduce wind curtailment and enhance the dispatching ability of the system. Muhammad et al. [10-13] proposed a model to optimize the capacity of the solar-windbattery hybrid system with the optimization objective of low cost of electricity consumption, which reduces the amount of abandoned electricity and the cost of power generation. Huang et al. [14] proposed a new and efficient decision-making tool to optimize the storage capacities for a grid-connected PV system, which not only obtain the most appropriate storage capacity, but also obtain the relationship between the utilization rates of renewable energy and storage capacities.

At present, the multi-energy complementarity power system considering concentrated solar power (CSP) with thermal storage is still in its initial stage of development. Therefore, it is very important to study the optimal capacity design of CSP-PV-Wind combined power generation system. In this paper, an improved particle swarm optimization (PSO) algorithm is used to optimize the installed capacity of CSP-PV-Wind combined power generation systems. The optimization objectives include: (1) The power is as close to the load as possible. (2) The minimum overall investment of the combined power supply; (3) The maximum annual total power generation revenue.

In this paper, Part 2 describes the optimization model of CSP-PV-Wind combined power generation system; Part 3 describes the operation strategy of CSP-PV-Wind combined power generation system; Part 4 gives a case analysis; Part 5 is the conclusions.

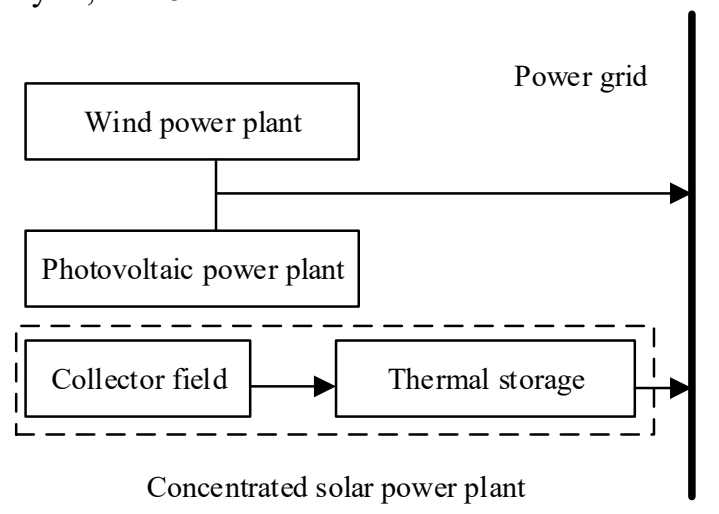

Fig.1. The structure of CSP-PV-Wind combined power generation system

\section{Optimal model of CSP-PV-Wind combined power generation system}

\subsection{Objective function}

The installation cost of CSP-PV-Wind combined power generation system is shown in (1). Considering the punishment factor, the cost of annual total power abandonment is shown in (2) and the cost of annual total supplementary capacity for insufficient load is shown in (3). Annual total generation revenue is in (4).

$$
\begin{aligned}
& f w_{1}=\left(r_{1} x+r_{2} y+r_{3} z\right) \\
& f w_{2}=v_{1} \text { Deltap }_{1} \\
& f w_{3}=v_{2} \text { Deltap }_{2} \\
& f w_{4}=v_{3} P
\end{aligned}
$$

where, $x, y$ and $z$ represent the installed capacity of Wind, PV and CSP respectively; Deltap ${ }_{1}$ is the annual total power abandonment; Deltap 2 is the annual total supplementary electricity for insufficient load; $P$ is the annual total power generation; $r_{1}, r_{2}$ and $r_{3}$ represent the investment cost of unit megawatt wind, PV and CSP respectively; $v_{1}, v_{2}$ and $v_{3}$ represent the abandoned power price, the price of supplementary power for insufficient load and feed-in tariff respectively.

The CSP-PV-Wind combined power generation system should meet the minimum investment cost, abandoned power cost and the supplementary power cost of insufficient load, and the maximum annual total power generation revenue. Thus, the objective function of the optimization model is shown in (5).

$$
\min f w_{1}=\min \left(a_{1} f w_{1}+a_{2} f w_{2}+a_{3} f w_{3}\right) /\left(a_{4} f w_{4}\right)
$$

where, $a_{1}, a_{2}, a_{3}$ and $a_{4}$ represent the weight coefficients of investment cost, power abandonment cost, supplementary power cost of insufficient load and annual total power generation revenue respectively.

\subsection{Constraint conditions}

During the whole calculation period (one year), the system should match the power supply curve with the load curve as much as possible. $p w(i, j), p v(i, j), p d(i, j)$, and $p l(i, j)$ are used to represent wind power, PV, CSP, and real-time load data at Time $j$ on Day $i$, respectively, which should meet the requirements of (6).

$$
p w(i, j)+p v(i, j)+p d(i, j)>p l(i, j)
$$

Due to the instability of new energy generation, the fluctuations of $p w(i, j), p v(i, j)$ and $p d(i, j)$ are severe, which generally cannot meet the real-time load demand. Therefore, the system needs to add energy storage units, which is treated as a power supply system in peak load period, and a load access system in lower valley period. In order to quantify the energy storage unit, the current storage capacity of CSP plant is set as HS, while HSmax is the maximum heat storage capacity of CSP plant. $H S$ needs to satisfy the following relationship at all times:

$$
H S<H S_{\max }
$$

The capacity of storage energy per hour is $\mathrm{m}$, and the formula are as follows:

$$
\begin{aligned}
& H S_{\max }>=H S+V_{\text {ex }} \text { eta } 1 \\
& H S-V_{\text {out }} / \text { eta }_{1}>=0 \\
& \text { eta }_{1} V_{\text {ex }}<=m \\
& V_{\text {out }} / \text { eta }_{2}<=m
\end{aligned}
$$

where, the power-to-heat rate of storage tank is $\mathrm{eta}_{l}$; the heat-to-power rate of storage tank eta $a_{2} ; V_{e x}$ represents 
the stored electricity per hour; and the $V_{\text {out }}$ represents the released thermal energy per hour.

\section{Operating strategy of CSP-PV-Wind combined power generation system}

The CSP-PV-Wind combined power generation system is mainly composed of wind farm, PV power plant and CSP plant with thermal storage, shown in Fig. 1. Operation strategies are as follows: (1) Firstly, if the power of wind and PV is larger than the load, wind and PV power generation are used to meet the load, CSP power generation is used for thermal storage, and surplus wind, PV and CSP power generation are abandoned. Secondly, if the power of wind and PV is less than the load, and the total power of wind, PV and CSP is larger than the load, the excess heat generated by CSP can be used for thermal storage. And if CSP power generation still has surplus, it will be abandonment. The specific operation strategy is shown in Fig. 2. (2) If the total power of wind, PV and CSP are less than the load, the thermal energy in the storage tank of CSP is used to supplement the power. If the load is still not satisfied, the external power supply is used for supplementing the power shortage. The specific operation strategy is shown in Fig. 3.

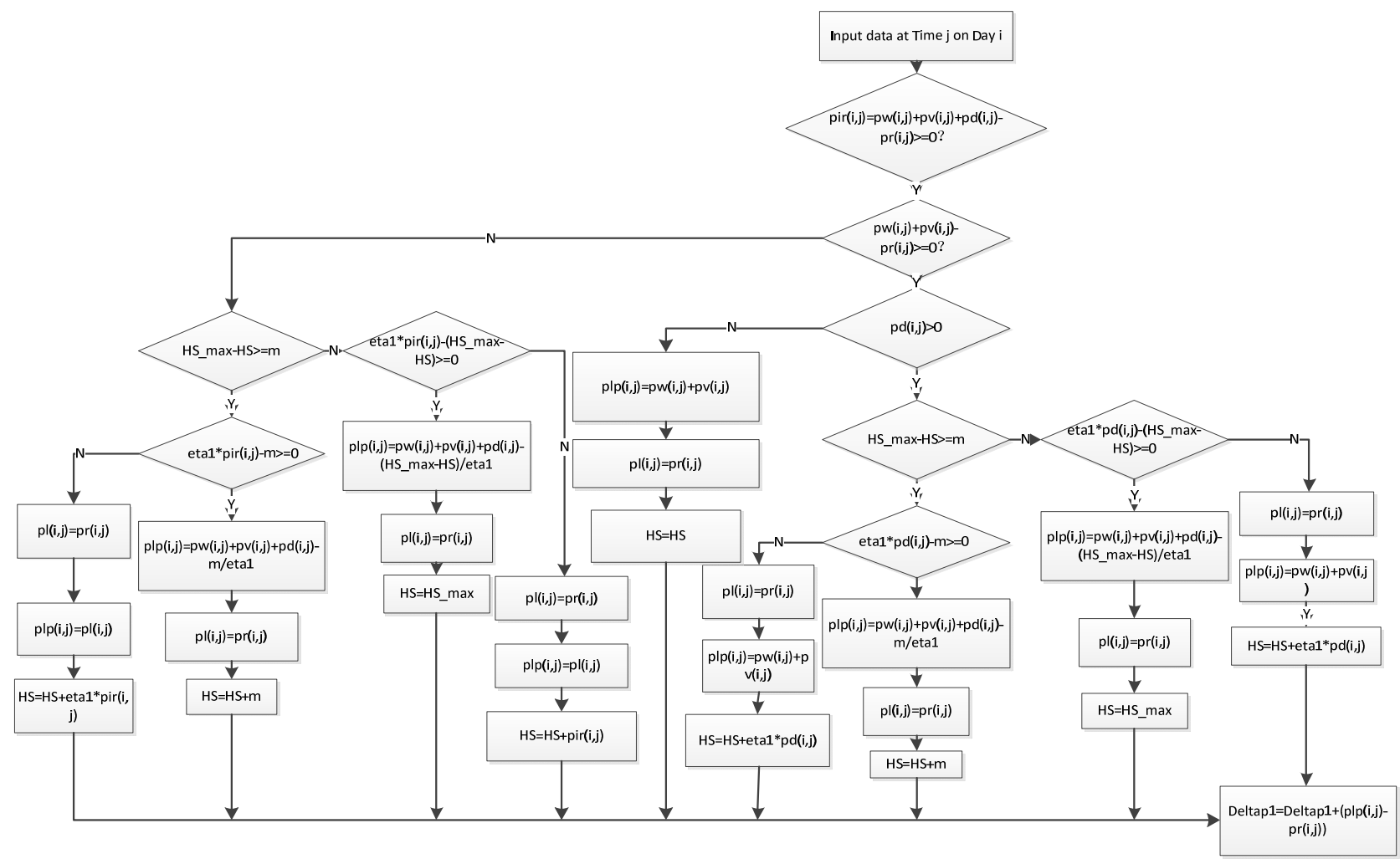

Fig. 2. Power generation strategy for storing thermal energy

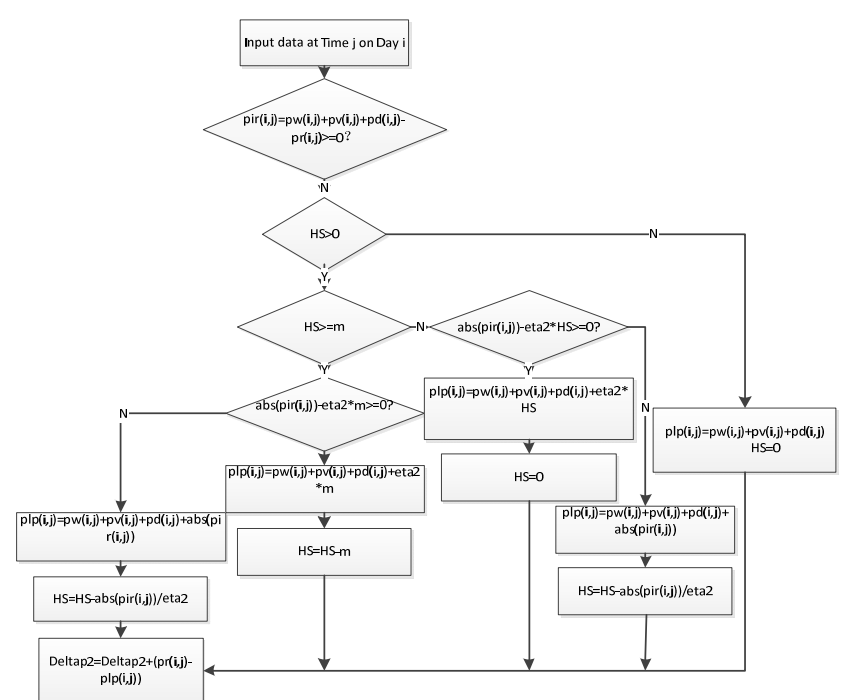

Fig.3. Power generation strategy for releasing thermal energy

\section{Case analysis}

In this case, the capacity of storage tank is 15 hours. The power curves of wind power, PV and CSP are obtained with the hour data of no-redundant wind or solar irradiation resources of per unit in a certain area in 2015 as shown in Fig. 4 to 6 . An improved PSO algorithm is used for calculating the capacity of CSP-PV-Wind combined power plant, which compared with that of PVWind combined power plant. The optimal capacity, SPSP, LPSP, investment cost and annual generation revenue of CSP-PV-Wind combined power generation system are shown in Table 1, while that of PV-Wind combined power generation system are shown in Table 2 . Considering the huge amount of annual load data and the power data, this data of PV-Wind and CSP-PV-Wind on one day in a year are extracted to show in Fig. 7. 


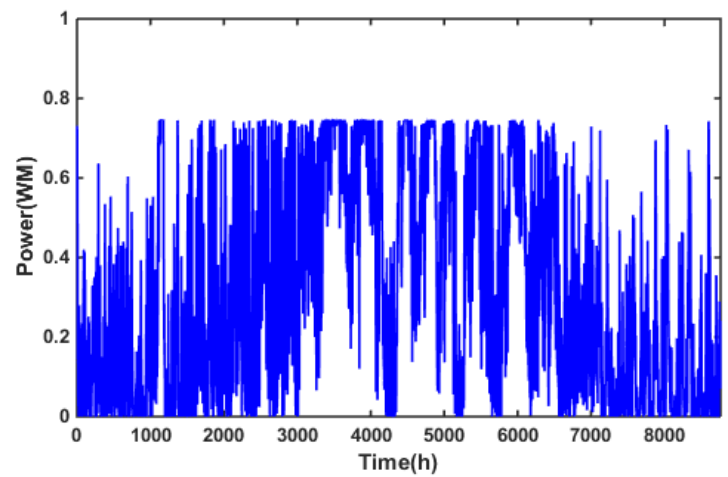

Fig. 4. The power curve of wind farm

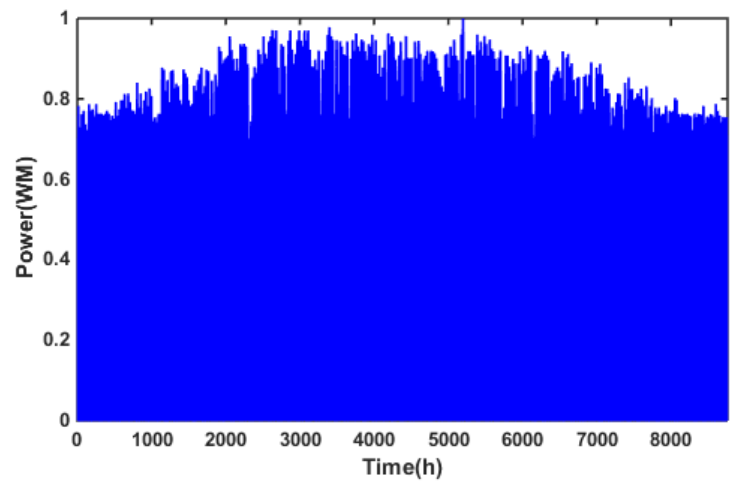

Fig. 6. The power curve of CSP plant

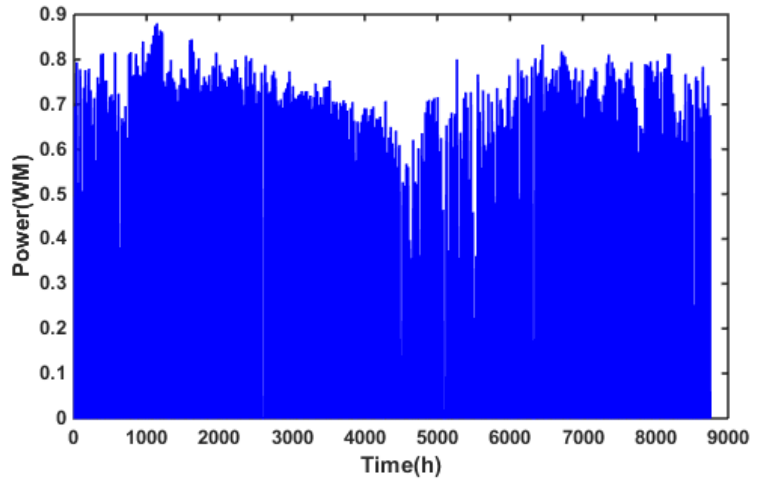

Fig. 5. The power curve of PV plant

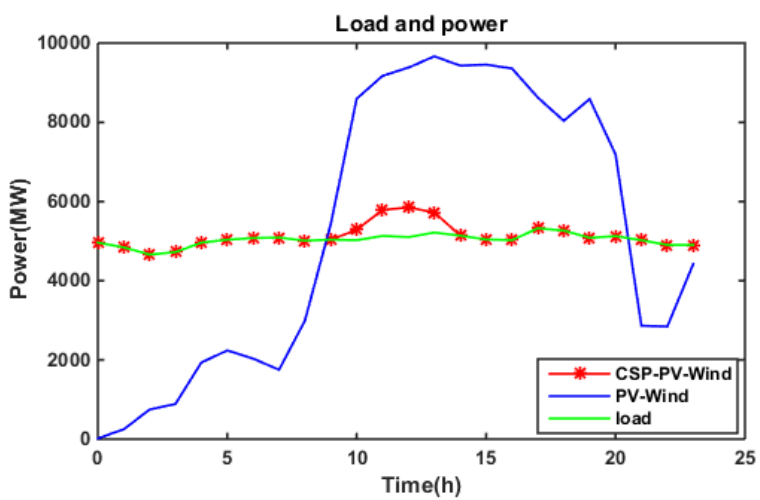

Fig. 7. The curve of load and power

Table 1. Optimal capacity and relative parameters of CSP-PV-Wind combined power generation system

\begin{tabular}{|c|c|c|c|c|}
\hline & First experiment & Fifth experiment & $\begin{array}{c}\text { The 15th } \\
\text { experiment }\end{array}$ & $\begin{array}{c}\text { The 20th } \\
\text { experiment }\end{array}$ \\
\hline Wind farm installation (MW) & 1960 & 1722 & 2012 & 2110 \\
\hline PV plant installation (MW) & 7115 & 7158 & 7179 & 7110 \\
\hline CSP plant installation (MW) & 13927 & 14122 & 13927 & 13936 \\
\hline SPSP & $11.59 \%$ & $10.78 \%$ & $12.18 \%$ & $12.77 \%$ \\
\hline LPSP & $11.43 \%$ & $11.42 \%$ & $11.31 \%$ & $11.19 \%$ \\
\hline Investment cost (RMB) & $5.8926 \mathrm{e}+11$ & $6.2331 \mathrm{e}+11$ & $6.6066 \mathrm{e}+11$ & $6.7311 \mathrm{e}+11$ \\
\hline Annual power generation revenue (RMB) & $2.3723 \mathrm{e}+10$ & $2.3726 \mathrm{e}+10$ & $2.3749 \mathrm{e}+10$ & $2.3775 \mathrm{e}+10$ \\
\hline
\end{tabular}

Table 2. Optimal capacity and relative parameters of PV-Wind combined power generation system

\begin{tabular}{|c|c|c|c|c|}
\hline Items & First experiment & Fifth experiment & $\begin{array}{c}\text { The 15th } \\
\text { experiment }\end{array}$ & $\begin{array}{c}\text { The 20th } \\
\text { experiment }\end{array}$ \\
\hline Wind farm installation (MW) & 1152 & 1170 & 1216 & 1196 \\
\hline PV plant installation (MW) & 7695 & 7674 & 8129 & 7936 \\
\hline SPSP & $42.52 \%$ & $43.51 \%$ & $44.02 \%$ & $45.09 \%$ \\
\hline LPSP & $42.24 \%$ & $41.77 \%$ & $43.85 \%$ & $43.64 \%$ \\
\hline Annual power generation revenue (RMB) & $1.4980 \mathrm{e}+11$ & $1.5165 \mathrm{e}+11$ & $1.5823 \mathrm{e}+11$ & $1.5529 \mathrm{e}+11$ \\
\hline
\end{tabular}


From Tables 1 to 2 and Fig. 7. it can be seen that the CSP-PV-Wind combined power generation system has smaller SPSP and LPSP than the PV-Wind combined power generation system, while the power generation quality and annual power generation revenue of CSPPV-Wind system are higher. However the installation capacity of CSP-PV-Wind system is larger and the cost of investment is higher than that of PV-Wind system. The surplus of power supply more than load in the figure is used for power abandonment. The optimized results reduce the SPSP and LPSP of the combined power system and improve the power generation quality.

\section{CONCLUSION}

In this paper, a capacity optimization method of CSPPV-Wind combined power generation system is proposed. In CSP-PV-Wind combined power generation system, Wind power and PV are mainly used for supply power while CSP is act as power peak shaving, frequency modulation and reactive power compensation. The minimum SPSP and LPSP, the minimum overall investment of the combined power supply and the maximum annual total power generation revenue are considered to be the optimization objectives. An improved PSO algorithm is used to optimize the installed capacity of CSP-PV-Wind combined power plant. The results show that the performance of SPSP and LPSP in CSP-PV-Wind combined power generation system are improved and the annual power generation revenue is increased compared with PV-Wind system. Due to CSP is introduced in this combined power system, the investment of cost would be increased. In the future, the strategies such as reducing the area of the collector field, increasing the capacity of the heat storage tank, and transforming the surplus energy of wind power and PV plant to thermal storage will be used for reducing the investment cost of the whole system, so as to achieve the effects of both improving the quality and reducing the cost of power generation.

\section{References}

1. Xu Darning, Kang Longyun and Cao Binggang, Acta Energiae Solaris Sinica, 27(2006): p. 919-922.

2. Li Dan, Tianjin University of Science and Technology, (in China,2017).

3. YANG Qi, et al., Automation of Electric Power Systems, 33(2009): p. 86-90.

4. Wu Hongbin, Chen Bin and Guo Caiyun, Transactions of the Chinese Society of Agricultural Engineering, 011. 27(4): p. 241-245.

5. TANG Xi-sheng and QI Zhi-ping, Study on an actively controlled battery/ultracapacitor hybrid in stand-alone PV system. Advanced Technology of Electrical Engineering and Energy, 25(2006): p. 3741,67.

6. ZHANG Dan-dan1, et al., Proceedings of the Chinese Society for Electrical Engineering, 27(2007): p. 26-31.

7. Yang, Y., et al., Energy Conversion and Management, 160(2018) p. 243-250.

8. Kamalinia, S. and M. Shahidehpour, IET Generation, Transmission \& Distribution, 4(2010): p. 940-951.

9. Chen, C., IET Generation, Transmission \& Distribution, 1(2007): p. 447-455.

10. Javed, M.S. and T. Ma, Energy Procedia, 158(2019) p. 6384-6392.

11. Buonomano, A., et al., Dynamic simulation and economic assessment. Energy, 155(2018) p. 174189.

12. Hiendro, A., et al., Energy, 59(2013) p. 652-657.

13. Kapsali, M., J.S. Anagnostopoulos, and J.K. Kaldellis, Appl. Energy, 99(2012) p. 430-444.

14. Huang, J., et al., Renewable Energy, 128(2018) p. 299-304. 